\title{
Big data cloud computing framework for low carbon supplier selection in the beef supply chain
}

\author{
Akshit Singh $^{1, *}$, Sushma Kumari', Hanif Malekpoor², Nishikant Mishra² \\ ${ }^{1}$ The University of Liverpool Management School, University of Liverpool, UK \\ ${ }^{2}$ Hull University Business School, University of Hull, UK
}

\begin{abstract}
Purpose - With the rapid economic development of nations across the globe, there is proportionate increment in corresponding carbon footprint. There are numerous counter measures proposed to mitigate it in terms of legislation and policy framing. However, they have a shortsighted vision of predominantly focusing on manufacturing and transportation industry thereby neglecting one of the significant contributor of global emissions- agricultural industry. Among all the agri-food products, beef has the highest carbon footprint and majority of its emission are generated in beef farms. The issue is more intensive in developing nations where most of global cattle are raised and simultaneously farmers are less informed and aware of resources/technology to address emissions from their farms. Therefore, there is need to raise awareness among farmers and thereby incorporate carbon footprint as a major cattle supplier selection attribute by abattoir and processor and integrate it as a standard practice in procurement of cattle.

Design/ methodology - A novel framework based on big data cloud computing technology is developed for eco-friendly cattle supplier selection. It is capable of measuring greenhouse gas emissions in farms and assimilate into the cattle supplier selection process. Fuzzy AHP, DEMATEL and TOPSIS method is employed to make an optimum tradeoff between conventional quality attributes and carbon footprint generated in farms to select the most appropriate supplier.

Findings - The proposed framework would assist in shedding the environmental burden of beef supply chain as the majority of carbon footprint is generated in beef farms. Moreover, the vertical coordination in the supply chain among farmers and abattoir, processor would be strengthened. The execution of the framework is depicted in case study section.

Originality- The literature is deficient of ecofriendly supplier selection in the agrifood sector particularly in developing countries. This study bridges the gap in the literature by proposing a novel framework to incorporate carbon footprint into traditional supplier selection process via an amalgamation of big data, ICT and Operations Research. The proposed framework would assist in mitigating the carbon footprint of beef products as they have highest emissions among all agri-food products. This framework is generic in nature and can be implemented in any food supply chain.
\end{abstract}

Keywords - Beef supply chain, supplier selection, carbon footprint, emerging economies, Big data.

*Corresponding author at: University of Liverpool, The University of Liverpool Management School, Chatham Street, Liverpool. L69 7ZH

Email: akshit.singh@liverpool.ac.uk 


\section{Introduction}

Recently, the reduction in carbon footprint is drawing the attention of researchers and academic practitioners around the globe. The major focus is confined to the manufacturing and their associated logistics only. The agriculture sector is also actively contributing to carbon emission, which is often being ignored. For example, agriculture sector accounts for around 9\% of the total carbon footprint of USA (the United States Environmental Protection Agency, 2014). Developed countries are looking at this matter seriously and taking active measures to curtail them. They have some serious targets of curbing their emission within a certain time limit. For example, European Union has a clear target of cutting down their emission levels by 40\% till the year 2030 (European Council, 2014). This ambitious target can only be achieved by reducing the emissions in all sectors including agriculture sector. In the past, a significant amount of work has been conducted in developed nations to mitigate the emissions at livestock farms, abattoir, processor and retailer. On the other hand, the developing countries or the emerging markets are lagging behind to address this issue. The nature of agriculture sector is different in developing nations and usually, farmers in these countries are not aware of the modern technology to mitigate the carbon emissions.

Beef production is the highest contributor to the carbon footprint as compared to all other products of agriculture activities (Food and Agriculture Organization of United Nations, 2013). Conventionally, the major focus of beef industries was to meet the demands of customers, which are improving quality (flavour, colour, and tenderness), reducing price, traceability and animal welfare. However, the awareness is growing gradually among customers for carbon footprint associated with all the edible products they are consuming. Simultaneously, there is a constant pressure from the government on beef industries to curb their emission or else their business might be jeopardized. The abattoir and processor is taking various steps to reduce the carbon emission at their end like reducing the emissions in their butchering and boning operations by employing renewable sources of energy. However, the $90 \%$ of the emissions occurring in the beef supply chain is taking place at beef farms. There is need to mitigate this and integrate it with the beef cattle supplier selection process by abattoir and processor. The main root causes are enteric fermentation and manure. The amount of carbon emitted at farm level depends on various factors such as the breed of the cattle, age, feeding pattern etc. Farmers collect an enormous amount of data pertinent to these factors in farms on daily basis. This data is huge and scattered in nature and resembles the salient features of big data i.e. volume, variety, velocity (Gang et al., (2016); Shuihua et al., (2016)). There are numerous methods described in the literature to measure carbon footprint. It is very complicated for a beef farmer to select an appropriate tool and use it. These carbon calculators are often very expensive. Therefore, it is quite a challenge for them to do the record keeping of carbon footprint. There is need to raise the awareness in farmers and to select the most eco-friendly beef cattle supplier. To overcome the above-mentioned issue, in this article, a big data cloud-computing framework for carbon minimization has been proposed. It has been demonstrated how big data cloud computing technology can help farmers to measure their carbon footprint in cost-effective way. This paper shows how the captured information of carbon footprint can be utilized by abattoir and processor in eco-friendly supplier selection of beef cattle, which could assist agri-food 
industrial practitioners in curbing their emissions. Simultaneously, on the theoretical front, it is one of the few studies in agri-food sector addressing the issue of ecofriendly supplier selection. This literature gap is addressed by proposing a framework built upon the conjunction of big data, ICT and operations research. This framework has universal attributes and can be mimicked/configured for any food supply chain.

The organization of this paper is as follows: The next section (section 2) consists of literature review. Section 3 contains the description of cloud computing technology. Problem formulation is mentioned in section 4. Section 5 consists of cloud-based framework for carbon minimization. The framework of supplier selection and evaluation and underpinning methodology followed is explained in section 6 . The case study section is illustrated in section 7. The managerial implications of this framework are highlighted in section 8. The conclusion of this paper is being described in section 9 .

\section{Literature review}

Peters et al., (2012) have done a comparative study of the carbon footprint associated with red meat supply chains in Australia with the global studies. Three supply chains viz. beef, sheep and premium beef from various geographical regions of Australia were taken into account. Their carbon footprint is measured using LCA (Life Cycle Assessment) method. It was concluded that red meat industries in Australia have average or below average carbon footprint in comparison to global studies. There was a revelation that feedlot based cattle are associated with a lesser carbon footprint as compared to grassland based cattle. Kythreotou et al., (2011) found out a technique to determine the greenhouse gas emissions occurring because of the energy consumption like LPG, diesel, electricity, etc. for breeding of cattle, poultry and pig in Cyprus. The consumption of energy from each energy source by livestock species and the corresponding greenhouse gas emission from these energy sources were calculated. The impact of anaerobic digestion and greenhouse gas emission due to transport is not being considered in this article. The results obtained were compared to the other major greenhouse gas emission sources in livestock breeding like enteric fermentation and manure management. Desjardins et al., (2012) have calculated the carbon footprint of beef in European Union, Canada, Brazil and USA. It was noticed that carbon footprint of beef production in these countries is declining in the past 30 years and the corresponding reasons were mentioned. They proposed to allocate the carbon emission to the byproducts of beef as well as offal, hide, fat and bones. Bustamante et al., (2012) have calculated the greenhouse gas emissions associated with breeding cattle in Brazil in the time period of five years from 2003 to 2008. Their root causes were explained. It was found out that the greenhouse gas emissions from cattle farming is contributing to almost half of the greenhouse gas emissions done by Brazil. Finally, certain policies were recommended for both public and private sectors to curtail the greenhouse gas emissions associated with the cattle farming. Ballerby et al., (2013) have calculated the greenhouse gas emissions from the supply chains of livestock starting from their production to consumption and the corresponding waste in EU27 in the year 2007. The major root causes of these emissions were livestock farms, LULUC (Land Use and Land Use Change) and food waste. It was suggested to reduce waste, consumption and production of beef products to curtail greenhouse gas emissions. There was a proposal of utilizing grassland-based farms for cattle breeding instead of intensive production for them. Schroeder et al., (2012) have determined the 
carbon footprint of two beef supply chains from the UK and one from Brazil. LCA techniques were used for this purpose and the phenomenon of carbon sequestration is included in them. It was observed that majority of emissions are occurring at farm end. There was a recommendation to increase the weaning rate and reduce the age of slaughter from thirty to twenty four months for mitigating the carbon footprint of the beef supply chain. Ogino et al., (2007) have evaluated the impact of cow-calf system on the environment in Japan. LCA techniques have been used and this study was confined to various operations and procedures involved in feed production, transport and animal welfare. The impact of one calf in its entire lifetime is being considered on the environment in form of greenhouse gas emission, acidification, eutrophication and energy consumption. There was a suggestion to reduce the calving interval by one month and increasing the weaning rate to mitigate the impact on the environment. Darkow et al., (2015) have demonstrated how logistics firms in food supply chains can enhance their businesses as compared to their rivals by aligning towards ecofriendly sustainable principles in their operations. Acquaye et al., (2014) has generated supply chain carbon maps for identifying hot spots of carbon emission so that they can be mitigated. It will also help in benchmarking with other supply chains of similar products and structures. Soosay et al., (2012) have identified lack of synergy between consumer preferences and allocation of resources by using sustainable value chain analysis. Singh et al., (2017) has developed consumer-centric beef supply chain by identifying the issues faced at downstream of supply chain via big data analytics (Twitter analytics). Shukla et al., (2017) have proposed a big data analytics approach to investigate the supply chain management issues within the food sector.

Supplier selection is primarily a Multi-Criteria Decision Making (MCDM) problem, which involves evaluation of various attributes and criteria. The literature on MCDM consists of numerous methodologies for this purpose. Freeman et al., (2015) have utilized the AHP (Analytic Hierarchy Process) and Entropy analysis for eco-friendly supplier selection for Chinese electro machinery manufacturer. Bai and Sarkis, (2014) have proposed a methodology to identify sustainable supply chain key performance indicators (KPI) and their application in sustainability performance evaluation. Rough set theory and sensitivity analysis have been used for this process. Then, DEA (Data Envelopment Analysis) is being utilized to compare the performances of the supply chains. Ulutas et al., (2016) developed a novel supplier evaluation and selection tool by employing amalgamation of fuzzy analytic hierarchy process, fuzzy complex proportional assessment and fuzzy linear programming and its potency were demonstrated on a Turkish textile firm. Shukla \& Kiridena, (2016) have proposed a decision support system to optimize the decision making at various stages of supply chain via application of the distributed multi-agent system. Park et al., (2018) have proposed a decision support system for sustainable supplier selection by taking into account triple bottom line attribute at regional level via application of multi-objective linear programming. Yu et al., (2018) suggested an eco-friendly supplier selection incentivized framework based on greenhouse gas emissions, which impulses the stakeholders within the supply chain stakeholders to take initiative in eco-friendly decisions. Jalalvand et al., (2011) developed an integrated method of DEA and PROMETHEE II. They used seven supply chains of the Iranian boiler industry and also procedures mentioned in SCOR 9.0 to show the applicability and strength of this method in comparing supply chains. 
In recent past, Decision Making Trial and Evaluation Laboratory (DEMATEL) has been widely employed for supplier evaluation and selection in the domain of supply chain management. Shen et al., (2012) proposed a supplier selection framework for food industry built upon the amalgamation of Analytic Network Process (ANP) and DEMATEL, which could assist a firm to optimize their material costs and thereby gain competitive advantage. Hsu et al., (2013) have suggested a DEMATEL model to identify the dominant criteria for carbon management within the context of green supply chains for enhancing the performance of suppliers in terms of mitigating their carbon emissions. Chang et al., (2011) have employed fuzzy DEMATEL in investigating the influential parameters while performing supplier selection in the domain of electronics industry for efficient supply chain management. Büyüközkan and Cifci, (2012) have recommended a novel mechanism based on fuzzy DEMATEL, fuzzy ANP and fuzzy TOPSIS for examining green suppliers in the setting of green supply chain management. BaykasoğLu et al, (2013) have proposed a fuzzy DEMTAEL and fuzzy hierarchical TOPOSIS model for addressing the truck selection problem within a land transportation firm.

Recently, there has been a significant rise in incorporating the big data analytics to achieve a competitive edge in supply chain management by various corporations across the globe. Seles et al., (2018) has identified and investigated the opportunities and threats posed by climate change towards organizations and the response strategy of organizations with respect to big data management. Zhao et al., (2017) has developed a model for low carbon supply chain based on amalgamation of big data analytics and multi-objective optimization, which mitigates the risk associated with greenhouse gas emissions, financial costs and hazardous elements. Zhang et al., (2017) have developed a big data analytics architecture for product lifecycle management (PLM) thereby overcoming the traditional barriers of deficiency of complete data and knowhow of efficient implementation of PLM along with cleaner production. Papadopoulos et al., (2017) have proposed a framework for resilience and sustainable supply chain network via analysis of unstructured big data mined from social media websites. The social media composed of responses of personnel and managers involved in disaster relief operation after the earthquake in Nepal in 2015. Lamba et al., (2018) have proposed a mixed integer nonlinear model for optimum supplier selection associated with precise lot sizes to reduce the financial expenses and environmental burden. The model captures and analyses real-time attributes of buyer and supplier such as capacity, financial cost and carbon caps, whose scale resembles to the characteristics of big data. The next section consists of description on cloud computing technology.

\section{Cloud computing technology}

Cloud computing has very modern architecture and is easy to adopt technology (Hutchinson et al., 2009). It has been used for quite a while in various sectors like automobile, banks, healthcare, retail, logistics and education (Al-Hudhaif and Alkubeyyer, 2011). There are various kinds of deployment models of this technology available depending on the requirement of the user. The collaboration among the companies is being increased by utilization of cloud (Xuan, 2012). The major advantages of cloud computing technology are reducing the cost to the company, faster deployment of computer resources and improved information visibility. 
Cloud Computing Technology (CCT) consists of three fundamental service delivery models, which are: Platform as a Service (PaaS), Software as a Service (SaaS) and Infrastructure as a Service (IaaS). The above-mentioned service delivery models are delivered via industry standards such as Service Oriented Architecture (SOA). Service providers such as Google Office, Netsuite, CRM, etc. does the support and maintenance for the SaaS application. The computing platform is provided by PaaS, which includes servers, networks, storage, etc. The software, its deployment and configuration settings are developed and taken care of by the consumer. For instance, Salesforge App Exchange, Joyent, etc. The network capacity, storage and miscellaneous computing resources on rent basis are provided by IaaS. IaaS also does the management of Operating System, applications, network components and storage. Examples of IaaS are Blizzard, Gogrid, etc.

The cloud deployment models can be classified into three categories, which are a public, private and hybrid cloud. The third party service provider hosts the public cloud. For example, Amazon. This is a very economical method to deploy IT solution by pay as you go concept. The very basic example of public cloud is Google Apps, which is utilized by numerous industries of different scales (Sen at al, 2011). A private cloud provides better control over the cloud infrastructure in addition to the services provided by the public cloud. It is more compatible with large-scale installations and is managed by third part service providers (Sean et al, 2011). A hybrid cloud possesses the characteristics of both public and private cloud. The organization keeps the control of confidential, business and mission-critical services whereas the non-critical information is sent to the public cloud (Sean et al., 2011).

The model described in figure 1 makes cloud-computing technology compatible for any industry irrespective of its size. The major companies having a robust IT infrastructure cannot have their own CCT, they can still get services from third-party service providers like Google. In that way, they can utilize all the benefits of CCT with minimal hassle. Those companies who have multiple branches and subsidiaries around the world can utilize the cloud to improve their connectivity. They can put their generic applications over the cloud via SaaS. CCT also provide an easy start-up facility for small and medium-sized firms. They don't have to bother about the scarcity of resources and can utilize the services provided by third-party service providers. These firms can also make their profile using SaaS to get connected to the global business. 


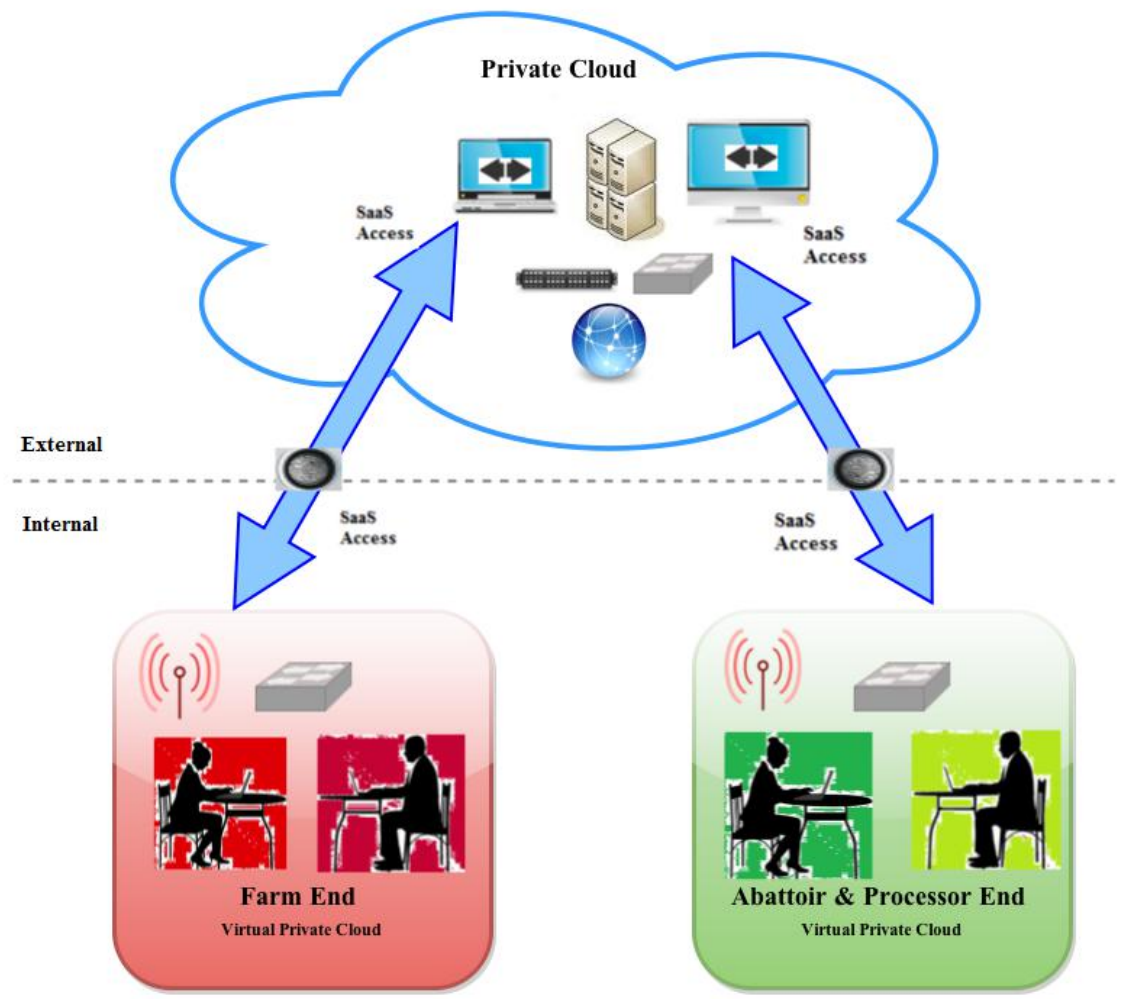

Figure 1 showing beef farmers being connected to abattoir and processor via a private cloud

\section{Problem formulation}

A beef supply chain consists of farm, abattoir, processor and retailer. Breeding of cattle is done in farms. When they reach finishing age, they are transferred to abattoir and processor. The cattle are slaughtered and processed into various beef products like mince, steak, joints, etc. These products are then sent to retailers, where customers buy them. The major concern of beef industry as a whole is quality (tenderness, flavour and colour), traceability, reducing price and animal welfare, etc. Usually, the abattoir and processor does their supplier selection of cattle based on quality, breed, diet, etc. They often ignore carbon footprint generated at farm end in raising their cattle.

The carbon footprint is generated in the whole beef supply chain from farm to retailer. The beef farms contribute to around $90 \%$ of carbon emission of the whole supply chain predominantly because of enteric fermentation and manure. The major reasons for carbon emission at abattoir and processor end is the energy consumed in their operations and the rendering of animal byproducts. The logistics involved in the whole beef supply chain also does considerable harm to the environment. The major reason is the distance between the stakeholders and then some secondary reasons like inefficient load optimization, temperature abuse of beef products, etc. The retailer of beef products is generating significant carbon footprint as well in their depots and stores. The primary reason for this emission is energy usage and poor forecasting of demand for beef products. All stakeholders of beef supply chain are taking preventive 
measures to reduce carbon emissions at their end like utilization of renewable energy sources, usage of eco-friendly fuel and load optimization in logistic vehicle, precise forecasting of demand of beef products, strong coordination among all stakeholders of beef supply chain, including more recycling content in packaging of beef products, environment friendly rendering of animal byproducts, etc. The highest emission occurs at farm end because of enteric fermentation, manure and fertilization used to grow feed for cattle. Enteric fermentation is a process taking place in the digestive system of cattle where their food is transformed into methane gas and released into the atmosphere. Methane is twenty five times more destructive than carbon dioxide in terms of their potential for global warming. Manure of cattle is also associated with numerous greenhouse gases like nitrous oxide, methane, ammonia and other oxides of nitrogen. Application of fertilizer on grasslands of beef farms or to the crops grown for cattle's feed releases different greenhouse gases like nitrous oxide, which is two hundred ninety eight times more potent than carbon dioxide. Usually, farmers don't pay attention to carbon minimization. During the discussion with the farmer, it was found that their focus is on quality, traceability, reduced price as these criteria are being considered during the process of supplier selection by the abattoir and processor. The beef farmers in emerging economies are generally deficient in resources and lack awareness to address the issue of generating carbon footprint at their farms. Their main objective is profit maximization. In past, there was a pressure from beef retailers and consumers on farmers to improve the tenderness, flavour and optimum fat content. Farmers have taken corresponding measures to improve these attributes to have a competitive advantage over their rivals. Now there is a need to include carbon footprint attribute in supplier selection process by abattoir and processor so that they can motivate farmers to raise their cattle by eco-friendly procedures. This article proposes a cloud-based framework, which will take into account carbon footprint of the beef farms along with conventional quality traits while purchasing cattle from beef farmers. This system is being described in next section.

\section{Cloud-based framework for carbon minimization}

In this study, a beef abattoir and processor is maintaining a private cloud, which can be accessed by them and their listed suppliers as shown in figure 1 . The listed beef farmers will open an account on the private cloud and enter the information of their cattle and farm as shown in figure 2. This information includes the breed of cattle being raised in their farms, their age, the feeding procedures followed, and a number of cattle in a farm, the average price of an individual breed of cattle, fatness score and conformation of cattle, compliance with traceability techniques (Hobbs, 1996). The characteristics of above-mentioned attributes are described in detail below:

a. Breed- Quality of meet varies with the breed of cattle. Meat derived from some of the cattle has premium quality whereas rest of them are of just mediocre quality, which is being sold at an economical price. The different breeds of cattle are also associated with the different amount of carbon footprint. It is basically dependent on the process of enteric fermentation. Usually, farms consist of breeds like Aberdeen Angus, Ayrshire, Limousin, etc. Particular farmer will select their type of breed and if they are raising more than one breed, they will select all of them and enter the number of cattle corresponding to each breed in the private cloud. 
b. Age - The age of cattle also affects the quality of beef. The cattle sent for slaughter at the age of around twenty four months generates less tender meat as compared to those of twenty months or lesser in age. The carbon footprint generated by cattle is directly proportional to the age of the cattle. Usually, farmers raise their cattle until the age of eighteen to twenty four months. Farmers will enter the age of their cattle of different breeds in private cloud.

c. Diet- The diet fed to the cattle affects the shelf life of the beef derived from them. The meat derived from grass-fed cattle has a considerably higher shelf life as compared to those raised on grain or mixed diet. However, in terms of carbon footprint, grain-based diet is having an advantage over grass-based diet. The cattle reach the finishing age earlier on the grain-based diet. Hence, fewer carbon emissions are generated by raising them. The farmer will enter the different dietary procedures followed for various breeds of cattle on a private cloud.

d. Average weight - There is certain weight range, which matches the specification of abattoir and processor. The cattle having weight more or lesser than this range would lead to overburden on a slaughterhouse in trimming the excess fat to make it lean to be able to sell it on premium price. Beef cattle have average weight from three hundred twenty to four hundred fifty kilograms. Farmers will enter the average weight corresponding to individual cattle.

e. Conformation - The category of conformation is evaluated by visual assessment of shape considering the development of muscles in hindquarter and carcass blockiness. Cattle with excellent conformation assists in producing high quality beef. When farmer will make its profile on a private cloud, it will enter the conformation values for each cattle over the cloud.

f. Fatness score -The fatness score is also determined by visual assessment of external fat development. They range from very lean to very fat category. Cattle having optimum fatness leads to higher quality meat. Farmers will enter the value of fatness score of their individual cattle on the cloud so that their cattle could be considered during the process of supplier selection.

g. Traceability - There is an increasing pressure of government legislation and customers on all stakeholders of the beef supply chain to incorporate traceability into their operations. They have to provide detailed information of the beef they are selling like the breed of the cattle, the location of farms where they were raised, and the diet fed to them, etc. It also helps the retailers and wholesalers of beef to charge a premium price to consumers for traceability associated with their products. Farmers will enter the status of their traceability standards into the cloud.

h. Price- The price of the cattle plays a crucial role in supplier selection by abattoir and processor. They look for the optimum quality cattle at a cheaper 
or reasonable price. The farmers will enter the desired price range for selling their cattle in the cloud.

The farmer has to store the information corresponding to all the aforementioned variables on a regular basis throughout the process of raising the cattle until they reach the finishing age. This information varies a lot due to the impact of internal and external factors of beef farming. For instance, cattle are raised in the house during the winter season and fed grain-based diet whereas in summer they are free to graze on the open grasslands. The energy consumption at beef farms also varies pertaining to these factors. Apart from keeping precise track of mode of energy consumed, farmers have to perform record keeping of the variation in diet and weight of cattle while they are fattened to reach their finishing age. Simultaneously, their conformation and fatness score is strictly monitored. The storage of this vast amount of information which varies very frequently and over the aggregate duration of raising cattle (24-30 months) could generate a colossal amount of data. As soon as farmers will enter this information, artificial intelligence (AI) present on the cloud will generate values corresponding to different supplier selection attributes. For example, carbon calculator will extract all information entered by the farmer and calculate the carbon emission generated by a farmer in raising their cattle. AI combines breed, conformation and fatness score to generate a value corresponding to the quality of beef. Thereafter, Fuzzy AHP, DEMATEL and TOPSIS will be used to make a tradeoff between all supplier selection attributes to select high-quality beef at a cheaper price with least carbon footprint through an MCDM evaluation of the suppliers. In the next section, the methodology used in this article is described in detail. 


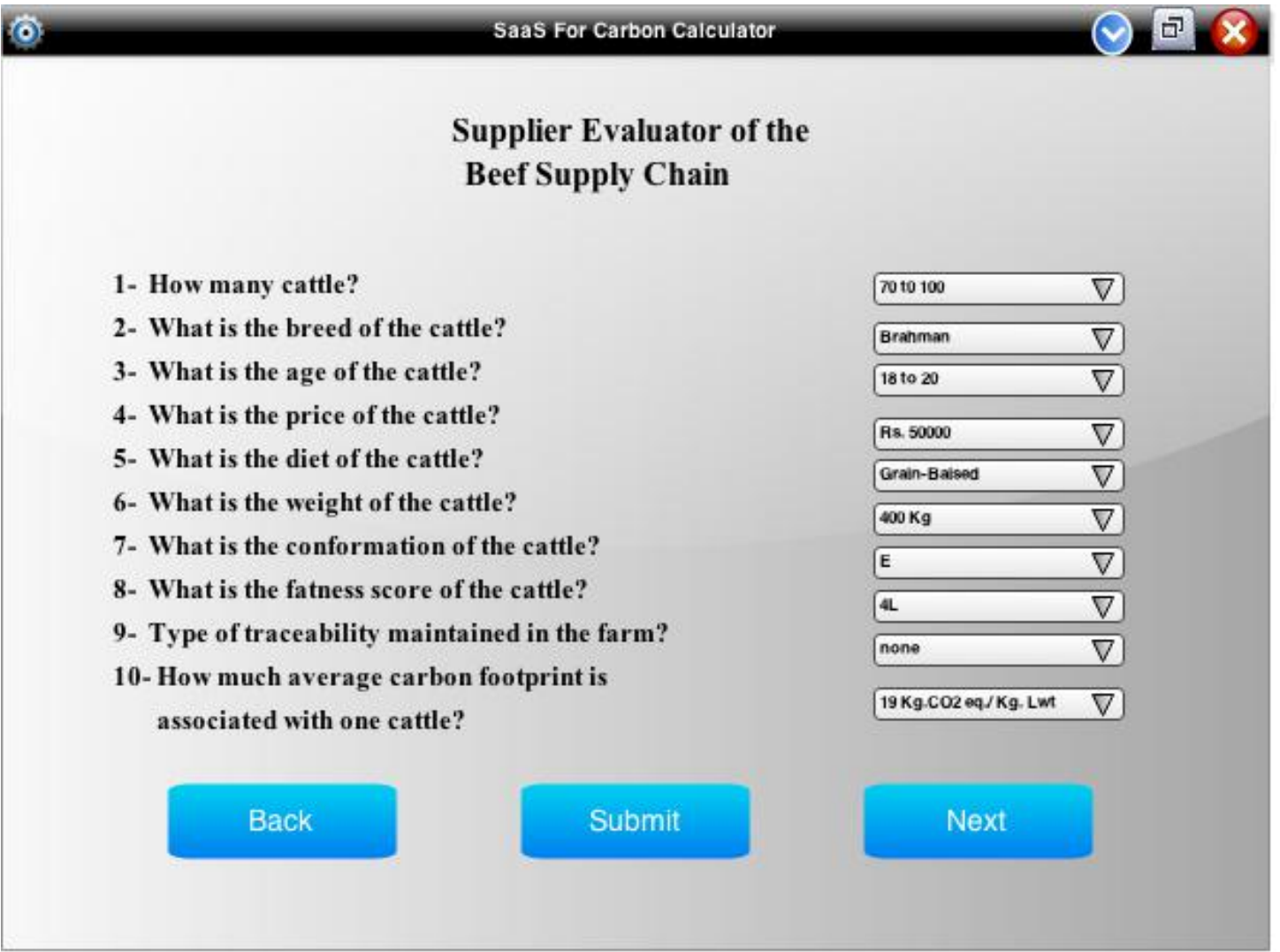

Figure 2. Showing information asked by carbon calculator uploaded on the cloud.

\section{Supplier evaluation and selection}

The process of supplier evaluation and ranking the suppliers is shown in figure 3 . The importance of each of the criterion varies for each decision maker. Thus, assigning the related importance weight to each of the criteria is the first step of the evaluation. DEMATEL and AHP are the two methods that are chosen to be applied for obtaining the importance weight in this paper. While AHP compares and discerns the relative importance of each of the criteria, DEMATEL emphasize the relations, cause and effects of each criterion on other criteria. Combination of the two weighting methods can give us a comprehensive importance weight of the criteria. After that, the TOPSIS is being used to evaluate the available suppliers with respect to the criteria. 


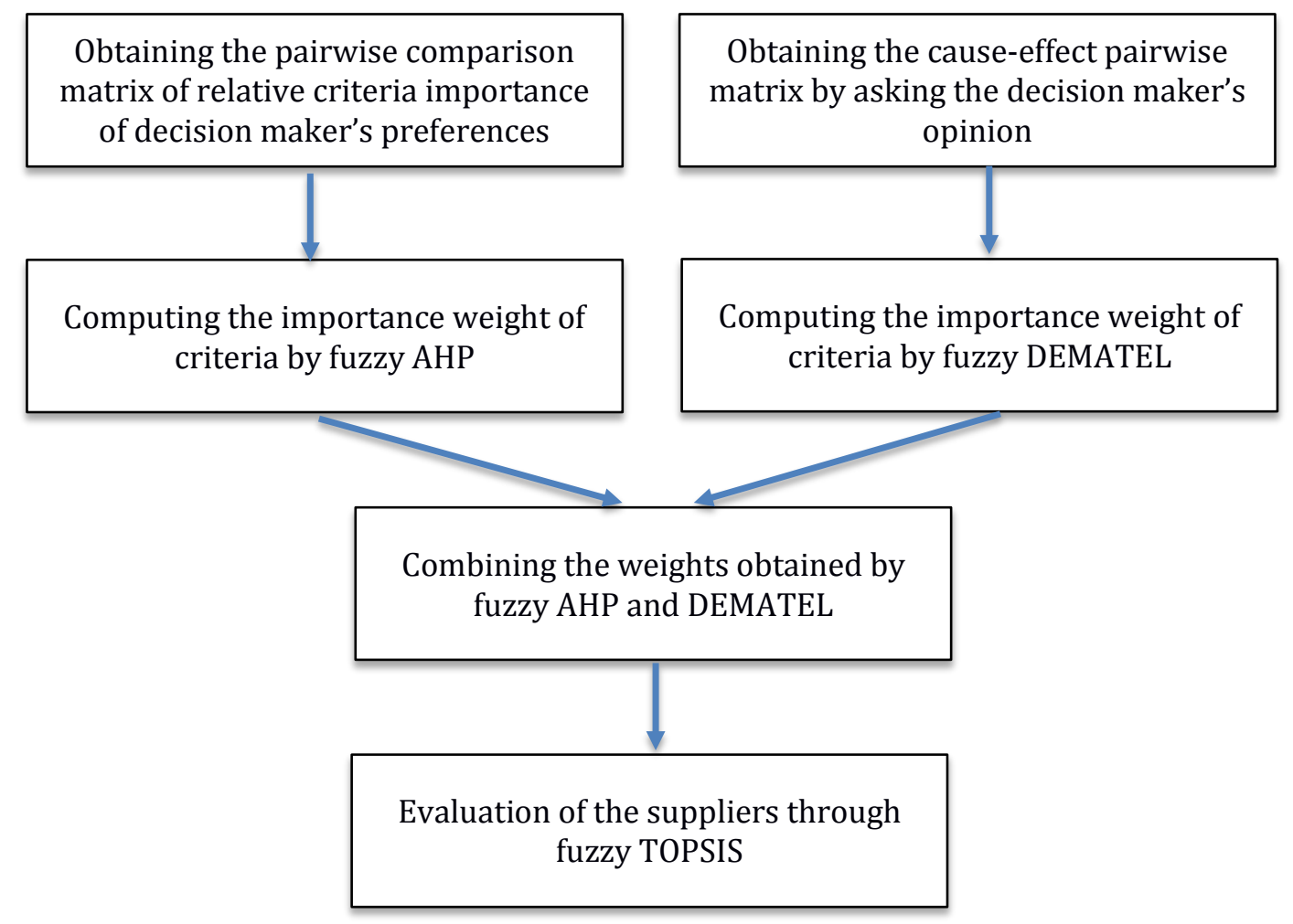

Figure 3 The solution process for supplier evaluation

The nature, scale and units of measurement are distinct for different variables of supplier selection of beef. In addition, some decision-makers are more confident in expressing their judgment by using familiar linguistic values rather than exact numeric exact values (Yurdakul and Ic, 2009). In order to deal with ambiguities, uncertainties and vagueness as well as above-mentioned problems, the use of fuzzy set theory has become popular among researchers. By application of fuzzy set theory, the decision-maker is able to incorporate unquantifiable information, incomplete information, non-obtainable information and partially ignorant facts into decision model (Kulak, Durmusoglu, \& Kahraman, 2005). Thus, the preferences and opinions of the decision makers are being expressed in linguistic fuzzy variables throughout the evaluations and the AHP, DEMATEL and TOPSIS are all executed by considering the data in fuzzy format.

One of the significant criteria of beef supplier selection is quality of beef. Quality is dependent on breed, conformation and fatness score of cattle. To obtain more precise values for the meat quality, the opinion of the decision maker regarding each of the sub-criterion for the quality of the meat is being gathered separately and then the average of these criteria has been considered in the main evaluation.

\subsection{Methodology:}

In this section, the methodologies being used in this paper has been explained. Firstly, the fuzzy set theory is mentioned, which is a base for all the techniques applied in this paper. Thereafter, the weight assigning methodologies, i.e. fuzzy AHP and fuzzy DEMATEL are presented. Finally, the steps of fuzzy TOPSIS are being described. 


\subsubsection{Fuzzy set theory}

Introduced by Zade et al., (1965), the mathematical aspects of fuzzy set theory assume that there is a universe of discourse $U$ and its fuzzy subset $A$ is represented mathematically by membership value denoted by $\mu_{\mathrm{A}}(x)$, with $x$ as an element of the universe of discourse, which conceptually denotes the grade of membership of $x$. The fuzzy subset $A$ is $A=\left\{\mu_{A}(u) / u \mid u \in U\right\}$ and the linguistic variables are represented in natural language by the name, e.g. $\mathrm{x}$ and the set term $\mathrm{S}(\mathrm{x})$ of the linguistic value of $\mathrm{x}$. In case of triangular fuzzy number (TFN), the membership function of $M=$ $\left(a_{i}, b_{i}, c_{i}\right)$ is based on equation (1) and this triplet is shown in figure 4:

$\mu_{M}(x)=\left\{\begin{array}{rlc}0 & \text { if } & x \leq a_{i} \\ \frac{x-a_{i}}{b_{i}-a_{i}} & \text { if } & a_{i} \leq x \leq b_{i} \\ \frac{b_{i}-x}{c_{i}-b_{i}} & \text { if } & b_{i} \leq x \leq c_{i} \\ 0 & \text { if } & x \geq c_{i}\end{array}\right.$

Now, let $\widetilde{M}$ and $\widetilde{N}$ be two triangular fuzzy numbers which are parametrized with two triplets of $\left(a_{1}, b_{1}, c_{1}\right)$ and $\left(a_{2}, b_{2}, c_{2}\right)$ respectively. Then, the following operational laws for these two number are applied based on 2 to 5 :

$$
\begin{aligned}
& \widetilde{M}+\widetilde{N}=\left(a_{1}+a_{2}, b_{1}+b_{2}, c_{1}+c_{2}\right) \\
& \widetilde{M}-\widetilde{N}=\left(a_{1}-a_{2}, b_{1}-b_{2}, c_{1}-c_{2}\right) \\
& \widetilde{M} \times \widetilde{N}=\left(a_{1} \cdot a_{2}, b_{1} \cdot b_{2}, c_{1} \cdot c_{2}\right) \\
& \frac{\widetilde{M}}{\widetilde{N}}=\left(\frac{a_{1}}{c_{2}}, \frac{b_{1}}{b_{2}}, \frac{c_{1}}{a_{2}}\right)
\end{aligned}
$$

The triangular fuzzy numbers are selected in this research not only because of their intuitive easiness for decision makers to calculate but also for proven effectiveness of modelling decision-making problems through them (Chang et al 2007, Zimmerman 1996).

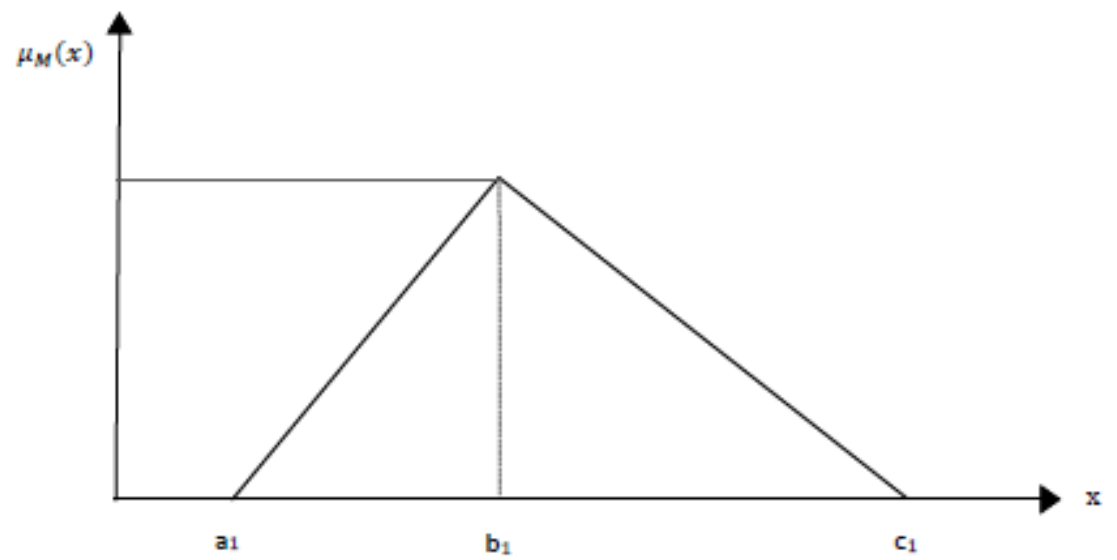

Figure 4 Triangular fuzzy number $M$

\subsubsection{Fuzzy AHP (FAHP)}

In this paper, we apply the methodology for FAHP, which has been first introduced by Chan et al., (2008). Assuming the criteria set of $C_{i}=\left\{c_{1}, c_{2}, \cdots, c_{i}\right\}$, and $M=$ 
$\left[\widetilde{M}_{i j}\right]$ as the com pairwise matrix the following steps should be followed to calculate the where:

$$
\widetilde{M}_{i j}=\left[\begin{array}{ccc}
\widetilde{M}_{11} & \cdots & \widetilde{M}_{1 n} \\
\vdots & \ddots & \vdots \\
\widetilde{M}_{n 1} & \cdots & \widetilde{M}_{n n}
\end{array}\right]
$$

Step 1: Computing $S_{k}=\left(S_{k, l}, S_{k, m}, S_{k, u}\right)$ values for each of the rows where $k$ indicates the row of the matrix by equation 7:

$S_{k}=\sum_{j=1}^{n} M_{k j} \times\left[\sum_{i=1}^{n} \sum_{j=1}^{n} M_{i j}\right]^{-1} \quad$ for $k=1, \cdots, n$

Step 2: Determining the degree of possibility of $S_{k} \geq S_{k^{\prime}}$ and $k \neq k^{\prime}$ through equation 8 and 9. If we have $S_{1}=\left(S_{1, l}, S_{1, m}, S_{1, u}\right)$ and $S_{2}=\left(S_{2, l}, S_{2, m}, S_{2, u}\right)$ then:

$\left\{\begin{array}{l}V\left(S_{1} \geq S_{2}\right)=1 \quad \text { if } S_{1, m} \geq S_{2, m} \\ V\left(S_{1} \geq S_{2}\right)=\operatorname{hgt}\left(S_{1} \cap S_{2}\right)\end{array}\right.$

In addition, we have:

$\operatorname{hgt}\left(S_{1} \cap S_{2}\right)=\frac{S_{1, u}-S_{2, l}}{\left(S_{1, u}-S_{2, l}\right)+\left(S_{2, m}-S_{1, m}\right)}$

Step 3: Calculating the criteria weight through equation 10:

$W^{\prime}\left(c_{i}\right)=\min \left\{V\left(S_{i} \geq S_{k}\right)\right\} \quad k=1, \cdots, n$ and $k \neq i$

Thus, the final weights obtained by fuzzy AHP are as equation 11:

$W^{\prime}=\left[W^{\prime}\left(c_{1}\right), \cdots, W^{\prime}\left(c_{n}\right)\right]$

Step 4: Obtaining the normalized weight vector by applying equation 12:

$W_{i}=\frac{W^{\prime}\left(c_{i}\right)}{\sum_{i=1}^{n} W^{\prime}\left(c_{i}\right)}$

\subsubsection{Fuzzy DEMATEL}

DEMATEL is a technique to construct a structural model and categorizing the criterion in cause or effect groups (Govindan et al., 2016). It was first introduced by Geneva Research Centre of the Battelle Memorial Institute in 1972 (Gabus and Fontela, 1972). The categorization of the criteria helps the decision makers to have a better understanding of the criteria. Moreover, it can be used to assign importance weights to each of them. If the problem is consisting of $n$ criteria, $C=\left\{C_{1}, C_{2}, \cdots, C_{n}\right\}$, the following steps explain the computing importance weight of each of the criterion based on fuzzy DEMATEL.

Step 1: constructing the pairwise influence matrix of the criteria as equation 13. 
$\widetilde{I M}_{k h}=\left[\begin{array}{ccc}\widetilde{I M}_{11} & \cdots & \widetilde{I M}_{1 n} \\ \vdots & \ddots & \vdots \\ \widetilde{I M}_{n 1} & \cdots & \widetilde{I M}_{n n}\end{array}\right]$

In equation (), each of the influence matrix element describes the level of influence the criterion of that row has on the values of the criterion in that column. These influences are being expressed in fuzzy linguistic terms in fuzzy DEMATEL.

Step 2: Normalizing the influence matrix $I M$ by equation 15 and obtaining the normalized influence matrix of $N M$ :

$\widetilde{N M}_{k h}=\left[\begin{array}{ccc}\widetilde{N M}_{11} & \cdots & \widetilde{N M}_{1 n} \\ \vdots & \ddots & \vdots \\ \widetilde{N M}_{n 1} & \cdots & \widetilde{N M}_{n n}\end{array}\right]$

Where:

$\widetilde{N M}_{k h}=\frac{\widetilde{I M}_{k h}}{\widetilde{R}}$

and

$$
=\left(\frac{\widetilde{I M}_{k \square, l}}{\widetilde{R}_{l}}, \frac{\widetilde{I M}_{k h, m}}{\widetilde{R}_{m}}, \frac{\widetilde{I M}_{k h, u}}{\widetilde{R}_{u}}\right)
$$

$\tilde{R}$

$=\left(\max \left(\widetilde{I M}_{k \square, l}\right), \max \left(\widetilde{I M}_{k \square, m}\right), \max \left(\widetilde{I M}_{k \square, u}\right)\right)$

Step 3: Obtaining the total-relation fuzzy matrix $\widetilde{T}$ based on equation 17 :

$\widetilde{T}_{k h}=\lim _{w \rightarrow \infty}\left(\widetilde{N M}_{k h}^{1}+\widetilde{N M}_{k h}^{2}+\cdots+\widetilde{N M}_{k h}^{w}\right)=\widetilde{N M}_{k h}\left(I-\widetilde{N M}_{k h}\right)^{-1}$

$\tilde{T}_{k h}=\left[\begin{array}{llc}\tilde{T}_{11} & \cdots & \tilde{T}_{1 n} \\ \vdots & \ddots & \vdots \\ T_{n 1} & \cdots & \tilde{T}_{n n}\end{array}\right]$

Where, $\tilde{T}_{k h}$ is a fuzzy number.

Step 4: Computing the sum of rows and columns of the total-relation matrix and calling them $\widetilde{D}_{i}$ and $\widetilde{R}_{i}$ respectively.

Step 5: Obtaining the weight of the criteria, $\widetilde{w}_{i}=\left(w_{i, l}, w_{i, m}, w_{i, u}\right)$ through equation 19 to 21:

$w_{i, l}=\sqrt{\left(\widetilde{D}_{i, l}+\widetilde{R}_{i, l}\right)^{2}+\left(\widetilde{D}_{i, l}-\widetilde{R}_{i, l}\right)^{2}}$
$w_{i, m}=\sqrt{\left(\widetilde{D}_{i, m}+\widetilde{R}_{i, m}\right)^{2}+\left(\widetilde{D}_{i, m}-\widetilde{R}_{i, m}\right)^{2}}$
$w_{i, u}=\sqrt{\left(\widetilde{D}_{i, u}+\widetilde{R}_{i, u}\right)^{2}+\left(\widetilde{D}_{i, u}-\widetilde{R}_{i, u}\right)^{2}}$

Step 6: Defuzzifying the fuzzy weights through equation 22: 
$w_{i}=\frac{w_{i, l}+2 w_{i, m}+w_{i, u}}{4}$

\subsubsection{Fuzzy TOPSIS}

Hwang and Yoon, (1981) introduced the TOPSIS which is a technique that ranks the alternative based on their distances from ideal positive and negative solution (PIS, NIS). The alternatives with closer distance to PIS and further distance from NIS are ranked higher by TOPSIS. Thus, the best alternative should not only have the shortest distance from the positive ideal solution but also should have the largest distance from the negative ideal solution. Ideal solutions are set of the best and worst performances of the alternatives within our criteria for PIS and NIS respectively. The following steps indicate how the Fuzzy TOPSIS calculated the evaluation of alternatives:

Assume, there are $m$ alternatives and $n$ criteria through which the performance of criteria is going to be evaluated. The decision Matrix D with m row and n column is formed based on equation (23).

$D=\left[x_{i j}\right]=\left[\begin{array}{ccc}\tilde{x}_{11} & \cdots & \tilde{x}_{1 n} \\ \vdots & \ddots & \vdots \\ \tilde{x}_{m 1} & \cdots & \tilde{x}_{m n}\end{array}\right]$

Where $x_{i j}=\left(a_{i j}, b_{i j}, c_{i j}\right)$

1- Normalize the decision Matrix using following formula and obtain $\tilde{R}=\left[\tilde{r}_{i j}\right]_{m \times n}$ :

$\tilde{r}_{i j}=\left(\frac{a_{i j}}{c_{j}^{*}}, \frac{b_{i j}}{c_{j}^{*}}, \frac{c_{i j}}{c_{j}^{*}}\right), \quad j \in B$

$\tilde{r}_{i j}=\left(\frac{a_{j}^{-}}{c_{i j}}, \frac{a_{j}^{-}}{b_{i j}}, \frac{a_{j}^{-}}{a_{i j}}\right), \quad j \in C$

In above formula, $\mathrm{B}$ is for a benefit criteria and $\mathrm{C}$ is for a criteria belongs to cost.

Also, $c_{j}^{*}=\max _{i} c_{i j}$ if $j \in C$ and $a_{j}^{-}=\min _{i} a_{i j}$ if $j \in B$.

2- Specify the Fuzzy Positive Ideal Solution (FPIS) and Fuzzy Negative Ideal Solution (FNIS) as below:

FPIS $=\left(r_{1}^{+}, r_{2}^{+}, r_{3}^{+}, \ldots . . r_{n}^{+}\right)$

FNIS $=\left(r_{1}^{-}, r_{2}^{-}, r_{3}^{-}, \ldots . . r_{n}^{-}\right)$

Where

$v_{j}^{+}=(p, p, p) \forall j=(1,1,1)$

$v_{j}^{-}=(k, k, k) \forall j=(0,0,0)$

3- Calculate the weighted distance of each alternative from positive and negative ideal solutions. The euclidean distance measure is used for this purpose. Distance $\mathrm{d}$ between two triangular fuzzy numbers (Let $A=\left(a_{1}, a_{2}, a_{3}\right)$ and $B=\left(b_{1}, b_{2}, b_{3}\right)$ ) can be calculated by the following formula:

$d(A, B)=\frac{1}{2}\left\{\max \left(\left|a_{1}-b_{1}\right|,\left|a_{3}-b_{3}\right|\right)+\left|a_{2}-b_{2}\right|\right\}$

If we assume the weight matrix $w_{j}=\left(w_{x j}, w_{y j}, w_{z j}\right)$ and each of our normalized Matrix arrays are $r_{i j}=\left(r_{x i j}, r_{y i j}, r_{z i j}\right)$ so then distance from FPIS can be calculated from formula (31): 
$d_{i}^{+}=\sum_{j=1}^{n} \frac{1}{2}\left\{\max \left(w_{x j}\left|r_{x i j}-1\right|, w_{z j}\left|r_{z i j}-1\right|\right)+w_{y j}\left|r_{y i j}-1\right|\right\}$

Distance from FNIS can be calculated from formula (32):

$d_{i}^{-}=\sum_{j=1}^{n} \frac{1}{2}\left\{\max \left(w_{x j}\left|r_{x i j}-0\right|, w_{z j}\left|r_{z i j}-0\right|\right)+w_{y j}\left|r_{y i j}-0\right|\right\}$

4- In the final step, the relative closeness coefficient to the ideal solution is computed through formula (33). The higher the value is, alternative obtain better rank.

$C R=\frac{d_{i}^{-}}{d_{i}^{+}+d_{i}^{-}}$

\section{Case Study}

This section demonstrates the execution of the proposed methodology. A beef abattoir and processor company is selected who aims to make their supplier selection on the grounds of carbon footprint generated in beef farms. There is a lot of pressure on this firm both from the government and the consumers to cut down the carbon emission in their supply chain. This company has ample resources to optimize the carbon emission at their end. However, the majority of emissions in their supply chain takes place at beef farms. In order to cut down the carbon emission in their beef supply chain, the abattoir and processor company has to make the operations of themselves and their supplier eco-friendly. The farmers have minimal knowledge and no mechanism to measure the carbon emissions and take preventive measures to mitigate them. They lack the awareness and resources to purchase a carbon calculator to quantify the carbon footprint in their farms. The carbon calculators are very expensive and often very sophisticated to utilize. The abattoir and processor firm will select an appropriate carbon calculator, which is both precise, user-friendly and install it on a private cloud maintained by them. All the potential suppliers (beef farmers) of this firm can access this calculator via cloud by just having an Internet connection. The farmers have been doing record keeping of the cattle in terms of their diet, weight, age, traceability, breed, fatness, conformation since they were born. This information is enormous in nature in terms of volume, variety and velocity as it has been stored for the duration of up to twenty four months. The beef farmers will make an account on the cloud and enter the details of cattle's final attributes as shown in figure 2. The values of farmer profile is being shown in Table 2 where the quality of the meat has been calculated based on table 1 . 
Table 1 Decision maker's opinion regarding quality of the beef

\begin{tabular}{|c|c|c|c|}
\hline Criteria & Breed & Confirmation & Fat Score \\
\hline S1 & VG & VG & VG \\
\hline S2 & P & VG & VG \\
\hline S3 & P & MG & G \\
\hline S4 & F & MG & F \\
\hline S5 & F & MG & VG \\
\hline S6 & G & G & G \\
\hline S7 & P & MG & F \\
\hline S8 & VG & F & MG \\
\hline S9 & MP & F & G \\
\hline S10 & MG & MG & G \\
\hline
\end{tabular}

Table 2 Information and decision maker's opinions of ten cattle suppliers in terms of various criteria

\begin{tabular}{|c|c|c|c|c|c|c|c|}
\hline Criteria & Quality of Meat & Age & Diet & $\begin{array}{c}\text { Average } \\
\text { Weight }\end{array}$ & Traceability & $\begin{array}{c}\text { Carbon } \\
\text { Footprint }\end{array}$ & $\begin{array}{c}\text { Price }(\times \\
1000)\end{array}$ \\
\hline S1 & {$[91010]$} & MP & VG & G & VG & F & {$[5051]$} \\
\hline S2 & {$[5.336 .667 .66]$} & MG & MG & MP & P & G & {$[4446]$} \\
\hline S3 & {$[45.667 .33]$} & MP & G & MG & MG & MG & {$[4142]$} \\
\hline S4 & {$[3.665 .667 .66]$} & G & F & G & VG & MG & {$[4547]$} \\
\hline S5 & {$[5.667 .338 .66]$} & VG & G & P & P & G & {$[4242.5]$} \\
\hline S6 & {$[7910]$} & MP & G & G & VG & MG & {$[46.547]$} \\
\hline S7 & {$[2.664 .336 .33]$} & MP & F & G & MG & F & {$[48.549]$} \\
\hline S8 & {$[5.667 .338 .66]$} & F & G & P & VG & VG & {$[42.543]$} \\
\hline S9 & {$[3.665 .667 .33]$} & MP & F & MP & P & F & {$[46.548]$} \\
\hline S10 & {$[5.667 .669 .33]$} & F & MG & VG & VG & VG & {$[40.541]$} \\
\hline
\end{tabular}

The carbon calculator installed on the cloud will process these details as shown in figure 4 and generate the results of carbon emission for these farmers. Numerous farmers operating in that province would submit their information on the cloud and this information would be enormous in scale resembling attributes of big data. This information would be carefully secured on the cloud infrastructure of abattoir and processor. Thereafter, the artificial intelligence present on the cloud will extract the breed, conformation and fatness score for all the farmers and the quality of the meat is calculated based on the average of the decision maker opinions regarding the breed, conformation and fatness score. The higher the value of the variable for quality, the better is the quality of meat. To effectively demonstrate the working of the proposed framework, ten suppliers have been considered in this case study. Now, abattoir and processor will set the importance of different attributes over the cloud depending on 
the demand of the market, consumer preference, country of sale, etc. This is done by constructing the AHP pairwise relative importance matrix and DEMATEL causeeffect relation matrix based on the decision maker's preferences. The relative importance and cause-effect relation matrixes for this case study based on an expert decision maker through linguistic fuzzy terms are illustrated in table 3 and 4.

Table 3 Decision maker's preferences for fuzzy AHP weight assigning

\begin{tabular}{|c|c|c|c|c|c|c|c|}
\hline Criteria & $\begin{array}{c}\text { Meat } \\
\text { quality }\end{array}$ & Age & Diet & $\begin{array}{c}\text { Average } \\
\text { weight }\end{array}$ & Traceability & $\begin{array}{l}\text { Carbon } \\
\text { footprint }\end{array}$ & Price \\
\hline $\begin{array}{c}\text { Meat } \\
\text { quality }\end{array}$ & - & Medium & Medium & $\begin{array}{c}\text { Medium } \\
\text { High }\end{array}$ & Medium & $\begin{array}{c}\text { Medium } \\
\text { High }\end{array}$ & Low \\
\hline Age & Very Low & - & Low & Low & Very Low & Low & Very Low \\
\hline Diet & Low & Medium & - & Medium & Low & Medium & Very Low \\
\hline $\begin{array}{c}\text { Average } \\
\text { weight }\end{array}$ & Very Low & Medium & Low & - & Low & Medium & Very Low \\
\hline Traceability & Medium & Medium & Low & $\begin{array}{c}\text { Medium } \\
\text { High }\end{array}$ & - & Medium & Low \\
\hline $\begin{array}{l}\text { Carbon } \\
\text { footprint }\end{array}$ & Low & Medium & Medium & $\begin{array}{l}\text { Medium } \\
\text { High }\end{array}$ & Low & - & Low \\
\hline Price & Low & $\begin{array}{l}\text { Medium } \\
\text { High }\end{array}$ & Medium & $\begin{array}{c}\text { Medium } \\
\text { High }\end{array}$ & Medium & Medium & - \\
\hline
\end{tabular}

Table 4 Decision maker's opinion for fuzzy DEMATEL weight assigning

\begin{tabular}{|c|c|c|c|c|c|c|c|}
\hline Criteria & $\begin{array}{c}\text { Meat } \\
\text { quality }\end{array}$ & Age & Diet & $\begin{array}{c}\text { Average } \\
\text { weight }\end{array}$ & Traceability & $\begin{array}{l}\text { Carbon } \\
\text { footprint }\end{array}$ & Price \\
\hline $\begin{array}{c}\text { Meat } \\
\text { quality }\end{array}$ & - & Very Low & Very Low & Very Low & Very High & High & Very High \\
\hline Age & High & - & Low & Very High & Very Low & Very High & $\begin{array}{l}\text { Medium } \\
\text { High }\end{array}$ \\
\hline Diet & Very High & Very Low & - & Very High & Very Low & High & $\begin{array}{c}\text { Medium } \\
\text { High }\end{array}$ \\
\hline $\begin{array}{c}\text { Average } \\
\text { weight }\end{array}$ & Low & $\begin{array}{l}\text { Medium } \\
\text { High }\end{array}$ & Low & - & Very Low & Medium & Low \\
\hline Traceability & Very High & Very Low & Very Low & Very Low & - & $\begin{array}{c}\text { Medium } \\
\text { High }\end{array}$ & Very High \\
\hline $\begin{array}{l}\text { Carbon } \\
\text { footprint }\end{array}$ & Very High & $\begin{array}{c}\text { Medium } \\
\text { High }\end{array}$ & $\begin{array}{c}\text { Medium } \\
\text { High }\end{array}$ & Very High & Low & - & Low \\
\hline Price & Very High & $\begin{array}{l}\text { Medium } \\
\text { High }\end{array}$ & $\begin{array}{l}\text { Medium } \\
\text { High }\end{array}$ & Low & Very High & Low & - \\
\hline
\end{tabular}


Table 5 is showing the individual and combined importance weight for each of the criteria.

Table 5 Importance weight for each criterion

\begin{tabular}{|c|c|c|c|c|c|c|c|}
\hline Methods & Meat & Age & Diet & $\begin{array}{c}\text { Average } \\
\text { weight }\end{array}$ & Traceability & $\begin{array}{c}\text { Carbon } \\
\text { footprint }\end{array}$ & Price \\
\hline $\begin{array}{c}\text { Fuzzy AHP } \\
\text { weights }\end{array}$ & 0.1940 & 0.0630 & 0.1063 & 0.1019 & 0.1619 & 0.1579 & 0.2149 \\
\hline $\begin{array}{c}\text { Fuzzy } \\
\text { DEMATEL } \\
\text { weights }\end{array}$ & 0.1466 & 0.1434 & 0.1507 & 0.1297 & 0.1177 & 0.1843 & 0.1276 \\
\hline $\begin{array}{c}\text { Combination } \\
\text { weights }\end{array}$ & 0.1703 & 0.1032 & 0.1285 & 0.1158 & 0.1398 & 0.1711 & 0.1712 \\
\hline
\end{tabular}

As soon as the importance of various attributes of supplier selection is defined, quality of meat and carbon footprint are calculated, the fuzzy TOPSIS method will generate the ranking of the supplier from most appropriate to least appropriate, which is shown in Table 6, while making a tradeoff between different attributes. To develop the medium value of fuzzy triangular number for price criteria, the average of the lower and upper bound of the price has been considered as the medium value. Based on the criteria set by abattoir and processor and farmer's profile, supplier 10 is the most appropriate supplier, who produces high-quality meat while generating minimum carbon emission. The abattoir and processor will start negotiating with these suppliers starting from the most appropriate supplier. When both the parties mutually agree, then the cattle are procured from the most fitting supplier. 
Table 6 Final fuzzy TOPSIS evaluation scores and ranking of the suppliers

\begin{tabular}{|c|c|c|}
\cline { 2 - 3 } \multicolumn{1}{c|}{} & Closeness coefficient & Rank \\
\hline Supplier 1 & 0.5482 & 8 \\
\hline Supplier 2 & 0.5294 & 5 \\
\hline Supplier 3 & 0.5663 & 3 \\
\hline Supplier 4 & 0.6356 & 6 \\
\hline Supplier 5 & 0.5508 & 2 \\
\hline Supplier 6 & 0.6688 & 9 \\
\hline Supplier 7 & 0.5235 & 4 \\
\hline Supplier 8 & 0.6245 & 10 \\
\hline Supplier 9 & 0.4375 & 1 \\
\hline Supplier 10 & 0.6823 & 8 \\
\hline
\end{tabular}

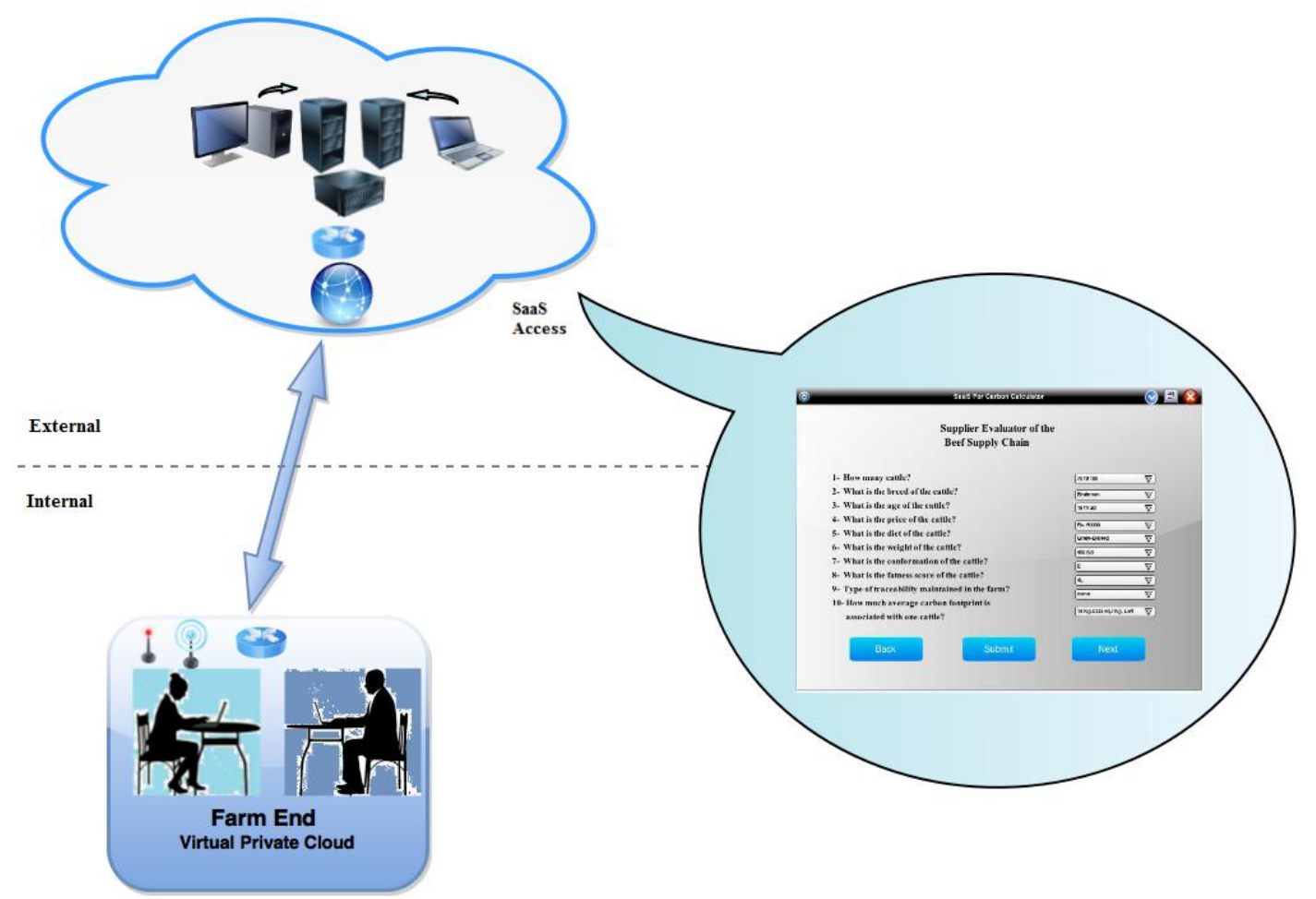

Figure 5 showing information entered by the farmer is being processed by carbon calculator uploaded on private cloud 


\section{Managerial Implications}

The proposed framework will help in minimization of carbon emissions at farm end. During the process of supplier selection by abattoir and processor, there will be a tradeoff made between the carbon emissions occurring at farm end and the conventional factors like breed, conformation, fatness score etc. Farmers are less aware of technology and also don't take carbon footprint into account while raising the cattle. However, there is a lot of government pressure on businesses to reduce their carbon footprint. The manager of abattoir and processor will have to curb emissions both at their premises and also carbon footprint generated by their suppliers to make their supply chain eco-friendly. Hence, they have to consider the carbon emissions at beef farms while doing the supplier selection. This framework will raise the connectivity of the manager of abattoir and processor to new potential cattle suppliers, as those farmers will also be able to connect to them via the cloud, which was out of range earlier. The manager of abattoir and processor will be able to target different segments of market preferring different quality parameters with this system. The cloud-based framework will help farmers to optimize their carbon emissions and other conventional factors as per the requirement of abattoir and processor. It will make them aware of modern trends and help them to raise their cattle as per the demand of abattoir and processor. Simultaneously, farmers will also learn from the good practices of the other farmers to reduce their carbon emission, as the relevant information of all the farmers will be visible on the cloud. The abattoir and processor will also upload guidelines on the cloud-based framework for farmers on procedures and techniques to reduce their carbon footprint and improve other factors. It will help the farmers to save money and develop an appropriate strategy. They will be aware of what breed of cattle needs to be raised, what to feed them, etc. Overall, this framework will develop a better coordination between farmers and abattoir \& processor, as there will be real-time information exchange among them.

\section{Conclusion}

Carbon emission is a concern for both developed and developing countries. All the attention in this context is being drawn towards the manufacturing industries. However, food industry also does significant harm to the environment. The carbon footprint generated by them are often understated and hence neglected. This article is focused on eco-friendly supplier selection of beef cattle by abattoir and processor. It shows how carbon footprint generated in beef farms can be taken into account along with breed, age, diet, the average weight of cattle, conformation, fatness score, traceability and price. Quality of beef is dependent on the combination of breed, conformation and fatness score of the cattle and the combination of these three criteria is carried out to a single criterion of meat quality. Then, quality, carbon footprint and other previously mentioned factors detrimental to supplier selection is assigned an importance weight according to the priority of customers and quality inspector of abattoir \& processor through fuzzy AHP and DEMATEL. Fuzzy TOPSIS method will process the information of various beef cattle suppliers in terms of above-mentioned factors and generate a ranking list of suppliers, starting form most appropriate to least appropriate supplier. The proposed technique in this study is being successfully demonstrated on beef industry in case study section. This research will not only help abattoir and processor in reducing their carbon footprint but will also help beef 
farmers to cut down their carbon emission. As most of the carbon footprint of beef supply chain is being generated in farms, this study will help in curbing these emissions. More farmers will be able to connect to abattoir and processor by using the cloud-based framework described in this article. These farmers will learn the modern trends associated with beef beyond conventional factors like price and breed. There will be an opportunity for farmers to learn from the good practices of other farmers in minimizing their carbon emissions and also improving in terms of other factors. Apart from these practical contributions, this study also makes a theoretical contribution as it is one of the pioneering research in the domain of eco-friendly supplier selection amongst agri-food industries, especially in emerging economies. Therefore, it addresses the void in existing studies by proposing a framework utilizing big data, ICT and operations research to accommodate carbon footprint into the traditional supplier selection process. Also, this framework is generic enough and can be applied to other industries. The limitations of this study is that internet connectivity is the fundamental requisite for this big data cloud computing framework, which is not readily accessible in emerging economies especially where beef farms are located in rural/remote areas. Therefore, future research should be directed to overcome this limitation with the advent of technology and sinking price of fiber-optic network. In addition, similar studies should be undertaken on other domains of food industry like pork, lamb and non-food industries like manufacturing industries. Furthermore, looking from a methodological aspect, the evaluation of the suppliers can be done through other types of numbers and methodologies regarding consideration of uncertainties in the decision maker's judgment like intuitionistic fuzzy numbers. Applying group decision making approaches, where the opinions of multiple decision makers are being applied in the process of the evaluations can be another future direction. Moreover, in order to enable the buyer (abattoir \& processor) to procure meat from multiple suppliers (farmers) and giving them more variety on purchasing options, multi-objective optimization techniques can be applied to compute the optimal share of purchase from each supplier.

\section{References}

Acquaye, A., Genovese, A., Barrett, J., \& Lenny Koh, S. C. (2014). Benchmarking carbon emissions performance in supply chains. Supply Chain Management: An International Journal, 19(3), 306-321.

Al-Hudhaif, S. A., \& Alkubeyyer, A. (2011). E-commerce adoption factors in Saudi Arabia. International Journal of Business and Management, 6(9), p122.

Bai, C., \& Sarkis, J. (2014). Determining and applying sustainable supplier key performance indicators. Supply Chain Management: An International Journal, 19(3), 275-291.

BaykasoğLu, A., KaplanoğLu, V., DurmuşOğLu, Z. D., \& ŞAhin, C. (2013). Integrating fuzzy DEMATEL and fuzzy hierarchical TOPSIS methods for truck selection. Expert Systems with Applications, 40(3), 899-907. 
Bellarby, J., Tirado, R., Leip, A., Weiss, F., Lesschen, J. P., \& Smith, P. (2013). Livestock greenhouse gas emissions and mitigation potential in Europe. Global change biology, 19(1), 3-18.

Bustamante, M. M., Nobre, C. A., Smeraldi, R., Aguiar, A. P., Barioni, L. G., Ferreira, L. G., Longo, K., May, P., Pinto, A.S. \& Ometto, J. P. (2012). Estimating greenhouse gas emissions from cattle raising in Brazil. Climatic change, 115(3-4), 559-577.

Büyüközkan, G., \& Çifçi, G. (2012). A combined fuzzy AHP and fuzzy TOPSIS based strategic analysis of electronic service quality in healthcare industry. Expert Systems with Applications, 39(3), 2341-2354.

Büyüközkan, G., \& Çifçi, G. (2012). A novel hybrid MCDM approach based on fuzzy DEMATEL, fuzzy ANP and fuzzy TOPSIS to evaluate green suppliers. Expert Systems with Applications, 39(3), 3000-3011.

Chang, B., Chang, C. W., \& Wu, C. H. (2011). Fuzzy DEMATEL method for developing supplier selection criteria. Expert systems with Applications, 38(3), 18501858.

Chang, Y. H., Chung, H. Y., \& Wang, S. Y. (2007). A survey and optimization-based evaluation of development strategies for the air cargo industry .International Journal of Production Economics, 106, 550-562.

Chen, M. F., \& Tzeng, G. H. (2004). Combining grey relation and TOPSIS concepts for selecting an expatriate host country. Mathematical and Computer Modelling, 40(13), 1473-1490.

Darkow, I. L., Foerster, B., \& von der Gracht, H. A. (2015). Sustainability in food service supply chains: future expectations from European industry experts toward the environmental perspective. Supply Chain Management: An International Journal, 20(2), 163-178.

Desjardins, R. L., Worth, D. E., Vergé, X. P., Maxime, D., Dyer, J., \& Cerkowniak, D. (2012). Carbon footprint of beef cattle. Sustainability, 4(12), 3279-3301.

European Council (October, 2014), Brussels. Retrieved from http://www.consilium.europa.eu/uedocs/cms_data/docs/pressdata/en/ec/145397.pdf

Food and Agriculture Organization of United Nations, 2013. Key facts and findings. Retrieved from http://www.fao.org/news/story/en/item/197623/icode/

Freeman, J., \& Chen, T. (2015). Green supplier selection using an AHP-EntropyTOPSIS framework. Supply Chain Management: An International Journal, 20(3), 327-340.

Gabus, A. and Fontela, E., (1972). World problems, an invitation to further thought within the framework of DEMATEL. Battelle Geneva Research Center, Geneva, Switzerland. 
Gang, W , Angappa, G, Eric W. T. N (2016). Distribution network design with big data: model and analysis, Annals of Operations Research, 1-13.

Govindan, K., Khodaverdi, R. and Vafadarnikjoo, A., (2016). A grey DEMATEL approach to develop third-party logistics provider selection criteria. Industrial Management \& Data Systems, 116(4), pp.690-722.

Hobbs, J. E. (1996). Transaction costs and slaughter cattle procurement: processors' selection of supply channels. Agribusiness: An International Journal, 12(6), 509-523.

Hsu, C. W., Kuo, T. C., Chen, S. H., \& Hu, A. H. (2013). Using DEMATEL to develop a carbon management model of supplier selection in green supply chain management. Journal of cleaner production, 56, 164-172.

Hutchinson, C., Ward, J., \& Castilon, K. (2009). Navigating the next-generation application architecture. IT professional, (2), 18-22.

Hwang, C.L., Yoon, K. (1981). Multiple Attribute Decision Making. In: Lecture Notes in Economics and Mathematical Systems 186. Springer-Verlag, Berlin.

Jalalvand, F., Teimoury, E., Makui, A., Aryanezhad, M. B., \& Jolai, F. (2011). A method to compare supply chains of an industry. Supply Chain Management: An International Journal, 16(2), 82-97.

Ju-Long, D. (1982). Control problems of grey systems. Systems \& Control Letters, 1(5), 288-294.

Kulak, O., Durmuşoğlu, M. B., \& Kahraman, C. (2005). Fuzzy multi-attribute equipment selection based on information axiom. Journal of materials processing technology, 169(3), 337-345.

Kuo, M.S., Liang, G.H., and Huang, W.C. (2006). Extension of Multicriteria Analysis with pairwise comparison under a fuzzy environment. International journal of approximate reasoning, 43(3), 268-285.

Kythreotou, N., Tassou, S. A., \& Florides, G. (2011). The contribution of direct energy use for livestock breeding to the greenhouse gases emissions of Cyprus. Energy, 36(10), 6090-6097.

Lamba, K., Singh, S. P., \& Mishra, N. (2018). Integrated decisions for supplier selection and lot-sizing considering different carbon emission regulations in Big Data environment. Computers \& Industrial Engineering.

Ogino, A., Orito, H., Shimada, K., \& Hirooka, H. (2007). Evaluating environmental impacts of the Japanese beef cow-calf system by the life cycle assessment method. Animal Science Journal, 78(4), 424-432. 
Papadopoulos, T., Gunasekaran, A., Dubey, R., Altay, N., Childe, S. J., \& FossoWamba, S. (2017). The role of Big Data in explaining disaster resilience in supply chains for sustainability. Journal of Cleaner Production, 142, 1108-1118.

Park, K., Kremer, G. E. O., \& Ma, J. (2018). A regional information-based multiattribute and multi-objective decision-making approach for sustainable supplier selection and order allocation. Journal of Cleaner Production, 187, 590-604.

Peters, G. M., Rowley, H. V., Wiedemann, S., Tucker, R., Short, M. D., \& Schulz, M. (2010). Red meat production in Australia: life cycle assessment and comparison with overseas studies. Environmental science \& technology, 44(4), 1327-1332.

Schroeder, R., Aguiar, L. K., \& Baines, R. (2012). Carbon footprint in meat production and supply chains. Journal of Food Science and Engineering, 2(11), 652.

Sean, M., Li, Z., Bandyopadhyay, S., Zhang, J., \& Ghalsasi, A. (2011). Cloud computing - The business perspective. Decision Support Systems, 51(1), 176-189.

Seles, B. M. R. P., de Sousa Jabbour, A. B. L., Jabbour, C. J. C., de Camargo Fiorini, P., Mohd-Yusoff, Y., \& Thomé, A. M. T. (2018). Business opportunities and challenges as the two sides of the climate change: Corporate responses and potential implications for big data management towards a low carbon society. Journal of Cleaner Production, 189, 763-774.

Shen, J. L., Liu, Y. M., \& Tzeng, Y. L. (2012). The cluster-weighted DEMATEL with ANP method for supplier selection in food industry. Journal of Advanced Computational Intelligence and Intelligent Informatics, 16(5), 567-575.

Shuihua, H., Yufang F., Bin C., \& Zongwei L. (2016). Pricing and bargaining strategy of e-retail under hybrid operational patterns. Annals of Operations Research, 1-22.

Shukla, N., \& Kiridena, S. (2016). A fuzzy rough sets-based multi-agent analytics framework for dynamic supply chain configuration. International Journal of Production Research, 54(23), 6984-6996.

Shukla, N., Mishra, N. \& Singh, A. (2017). Understanding the Food Supply Chain using Social Media Data Analysis, 7th International Conference on Advances in Information Mining and Management (IMMM), Venice, Italy

Singh, A., Mishra, N., Ali, S. I., Shukla, N., \& Shankar, R. (2015). Cloud computing technology: Reducing carbon footprint in beef supply chain. International Journal of Production Economics, 164, 462-471.

Singh, A., Shukla, N., \& Mishra, N. (2017). Social media data analytics to improve supply chain management in food industries. Transportation Research Part E: Logistics and Transportation Review.

Soosay, C., Fearne, A., \& Dent, B. (2012). Sustainable value chain analysis-a case study of Oxford Landing from "vine to dine". Supply Chain Management: An International Journal, 17(1), 68-77. 
Tseng, M. L., Tan, R. R., Chiu, A. S., Chien, C. F., \& Kuo, T. C. (2018). Circular economy meets industry 4.0: Can big data drive industrial symbiosis?. Resources, Conservation and Recycling, 131, 146-147.

Ulutas, A., Shukla, N., Kiridena, S., \& Gibson, P. (2016). A utility-driven approach to supplier evaluation and selection: empirical validation of an integrated solution framework. International Journal of Production Research, 54(5), 1554-1567.

United States Department of Agriculture, Foreign Agricultural Service. (April 2015). Livestock and Poultry: World Markets and Trade. Retrieved from http://apps.fas.usda.gov/psdonline/circulars/livestock_poultry.PDF

United States Environmental Protection Agency, 2014. Sources of Greenhouse gas emissions. $\quad$ Retrieved from http://www.epa.gov/climatechange/ghgemissions/sources/agriculture.html

Xuan, X. (2012). From cloud computing to cloud manufacturing. Robotics and computer-integrated manufacturing, 28(1), 75-86.

Yu, F., Yang, Y., \& Chang, D. (2018). Carbon footprint based green supplier selection under dynamic environment. Journal of Cleaner Production, 170, 880-889.

Yurdakul, M. and Iç, Y.T., (2009). Analysis of the benefit generated by using fuzzy numbers in a TOPSIS model developed for machine tool selection problems. Journal of materials processing technology, 209(1), pp.310-317.

Zadeh, L.A., 1965. Fuzzy sets. Information and Control, 8, 338-353.

Zhang, Y., Ren, S., Liu, Y., \& Si, S. (2017). A big data analytics architecture for cleaner manufacturing and maintenance processes of complex products. Journal of Cleaner Production, 142, 626-641.

Zhao, R., Liu, Y., Zhang, N., \& Huang, T. (2017). An optimization model for green supply chain management by using a big data analytic approach. Journal of Cleaner Production, 142, 1085-1097.

Zimmermann, H. J. (2001). Fuzzy set theory-and its applications. Springer Science \& Business Media. 